\title{
FAKTOR-FAKTOR YANG MEMPENGARUHI EMPLOYEE PERFORMANCE PADA PEGAWAI DITJEN PAJAK DI JAKARTA
}

\author{
Maulana Hidayat ${ }^{1}$ \\ Prasetyo Hadi $^{2}$ \\ Rusdi Musa Ishaq ${ }^{3}$
}

\author{
Fakultas Ekonomi dan Bisnis Universitas Pembangunan Nasional Veteran \\ Jakarta, DKI Jakarta, Indonesia \\ Maulanahidayat2013@gmail.com,prasetyohadi1960@gmail.com \\ rusdi.ishaq@gmail.com
}

\begin{abstract}
ABSTRAK
Penelitiaan ini merupakan penelitian kuantitatif yang bertujuan untuk mengetahui pengaruh Talent Management dan Knowledge Management terhadap Employee Performance melalui Employee Retention. Populasi dalam penelitian ini adalah pegawai Talent Ready Now Direktorat Jenderal Pajak di DKI Jakarta. Ukuran sampel diambil sebanyak 100 responden, dengan metode non probability sampling dengan perposive sampling. Pengumpulan data dilakukan melalui penyebaran kuisioner. Teknik analisiss yang digunakan adalah metode analisis PLS (Partial Least Square). Hasil penelitian ini menunjukan bahwa (1) Talent Management berpengaruh signifikan dan positif terhadap Employee Performance (2) Talent Management secara tidak langsung tidak berpengaruh signifikan dan negatif terhadap Employee Performance melalui Employee Retention (3) Knowledge Management berpengaruh signifikan dan positif terhadap Employee Performance dan (4) Knowledge Management secara tidak langsung berpengaruh signifikan dan positif terhadap Employee Performance melalui Employee Retention.

Kata Kunci: Talent Management, Knowledge Management,Employee Performance, Employee Retention
\end{abstract}

\begin{abstract}
This research is a quantitative study that aims to determine the effect of Talent Management and Knowledge Management on Employee Performance through Employee Retention. The population in this study are Talent Ready Now employees at the Directorate General of Tax whose work location is in DKI Jakarta. The sample size was taken as many as 100 respondents, with nonprobability sampling methods especially perposive sampling. Data collection was carried out through questionnaires. The analysis technique used is the PLS (Partial Least Square) analysis method. The results of this study indicate that (1) Talent Management has a significant and positive effect on Employee Performance (2) Talent Management indirectly has no significant and negative effect on Employee Performance through Employee Retention (3) Knowledge Management has a significant and positive effect on Employee Performance (4) Knowledge Management indirectly has a significant and positive effect on Employee Performance through Employee Retention

Keywords: Talent Management, Knowledge Management, Employee Performance, Employee Retention
\end{abstract}




\section{PENDAHULUAN}

Sumber Daya Manusia (SDM) adalah unsur strategis dalam organisasi untuk mensukseskan setiap misi organisasi, dimana SDM berfungsi sebagai banchmark dalam menentukan arah kebijakan sesuai dengan tujuan organisasi. Maksimalisasi kinerja karyawan dapat dilakukan dalam rangka mencapai tujuan organisasi yang ideal. Dalam hal ini, Faktor Individu yang termasuk juga talent dan knowledge yang merupakan kapasitas individu yang mampu mempengaruhi kinerja karyawan(Mahmudi, 2015).

Lahirnya Undang Undang No. 5 tahun 2014 tentang Aparatur Sipil Negara (ASN) diantara tujuannya adalah untuk mengoptimalkan pengelolaan atau manajemen SDM ASN di Indonesia, dimana pada pasal 51 undang-undang tersebut mengamanatkan agar Manajemen ASN diselenggarakan berdasarkan Sistem Merit. Sistem Merit adalah kebijakan dan manajemen ASN yang berdasarkan pada kualifikasi, kompetensi, dan kinerja secara adil dan wajar dengan tanpa membedakan latar belakang politik, ras, warna kulit, agama, asal usul, jenis kelamin, status pernikahan, umur, atau kondisi kecacatan. Sebagai turunan dari undang-undang tersebut, pemerintah menetapkan Peraturan Pemerintah nomor 11 tahun 2017 tentang Manajemen PNS, dimana pada pasal 134 dari peraturan tersebut disampaikan bahwa salah satu kriteria Instansi Pemerintah telah menerapkan Sistem Merit adalah memiliki manajemen karir yang terdiri dari perencanaan, pengembangan, pola karir, dan kelompok rencana suksesi yang diperoleh dari manajemen talenta". Salah satu instansi pemerintah yang telah menerapkan manajemen talenta adalah Kementerian Keuangan yaitu melalui "Peraturan Menteri Keuangan Nomor 60/PMK01/2016 tanggal 11 April 2016 tentang Manajemen Talenta Kementerian Keuangan sebagaimana telah diubah dengan Peraturan Menteri Keuangan Nomor 161/PMK.01/2017 tanggal 14 November 2017”'.

Sejak tahun 2009, Direktorat Jenderal Pajak (DJP) telah melaksanakan reformasi birokrasi jilid dua yang di antara fokus utamanya adalah pembenahan Sumber Daya Manusia (SDM). Bentuk reformasi SDM tersebut dilakukan secara menyeluruh dari fungsi pengembangan organisasi, workforce planning, Recruitment, Seleksi, Administrasi kepegawaian, pelatihan kerja, manajemen kinerja, manajemen karir, kompensasi hingga pengawasan internal. Dalam menjalankan proses pembangunan manajemen SDM tersebut, DJP telah membuat panduan dan pedoman pengembangan manajemen SDM berbasis kinerja dan kompetensi yaitu Cetak Biru Manajemen SDM Direktorat Jenderal Pajak. Program pengembangan SDM yang telah dilakukan yaitu: Program Penghargaan Kinerja Pegawai (PKP), Program tugas belajar, pendidikan di luar kedinasan, pendidikan dan pelatihan, serta penugasan Short Course, On-the-Job Training (OJT), E-Learning, In-House Training (IHT), dan Leadership Development Program (LDP).

Pengelolaan pengetahuan DJP dikembangkan dengan upaya mengintegrasikan 
seluruh pengetahuan DJP melalui slogan Kompatriot (Knowledge Management Pajak Terintegrasi dan Otonom). Beberapa kegiatan yang telah dilakukan terkait Kompatriot antara lain, yaitu: pembuatan kajian pengelolaan pengetahuan; benchmarking best practice pengelolaan pengetahuan oleh organisasi-organisasi besar Indonesia (Pertamina, United Tractor, BNI, Binus University) melalui keikutsertaan pada MAKE (Most Admired Knowledge Enterprise) Study; pembuatan wadah berbagi pengetahuan dengan nama Tax Talk; pelaksanaan kegiatan penghimpunan pengetahuan tacit, yaitu pengetahuan yang berisi tips dan trik yang umumnya diperoleh dari pengalaman; dan pembuatan platform tunggal berbasis confluence untuk mengintegrasikan web/aplikasi pengelolaan pengetahuan sektoral melalui metode single sign on.

Di tahun 2018, Direktorat Jenderal Pajak (DJP) telah melaksanakan program pengembangan SDM dengan konsep manajemen talenta. Program yang dilakukan DJP antara lain melakukan rekrutment calon talen pengisian jabatan pengawas dan administrator melalui uji kompetensi; melaksanakan pelatihan digital talent; melaksanakan workshop manajemen talenta dan workshop talent development bagi pegawai yang telah masuk dalam talent pool; dan melakukan mutasi serta promosi pegawai berdasarkan konsep manajemen talenta (Laporan Kinerja DJP, 2018)(Laporan Kinerja DJP, 2018)

Pelaksanaan penerapan manajemen talenta di DJP melalui beberapa proses, antara lain analisis kebutuhan Talent dan Jabatan Telent, "merupakan tahapan penghitungan jumlah kebutuhan talent yang akan dikelola/dikembangkan dalam manajemen talenta". Penetapan jabatan target dilakukan dengan memperhatikan klasifikasi unit kerja, klasifikasi wilayah, potensi penerimaan, kondisi sosiokultural dan politis wilayah, serta peringkat jabatan pada jabatan target.

Identifikasi calon Talent, yang dilakukan antara lain: "pemetaan pegawai, seleksi administrasi, pemantauan rekam jejak dan integritas, konfirmasi calon talent, dan pemeringkatan. Pada proses pemetaan pegawai, para pegawai dipetakan menggunakan diagram pemetaan berdasarkan kinerja dan kompetensinya sehingga pegawai yang berkinerja tinggi dan memiliki kompetensi paling luas (box IX) akan dijadikan telent". Dengan data dan informasi yang telah dikumpulkan, ditentukan daftar nama calon talent (short list) yang akan dibawa ke forum pimpinan unit.

Forum Pimpinan Unit, yang dilakukan adalah "menetapkan jabatan target yang akan diisi oleh talent dan menetapkan talent dari daftar terpilih calon talent. Forum pimpinan unit dapat memutuskan apakah seorang pegawai masuk dalam talent pool atau tidak berdasarkan rekomendasi atasan langsungnya atau bukti-bukti lain yang dapat dipertanggungjawabkan kebenarannya". Pengembangan Talent dilakukan dengan berbagai kegiatan diantaranya adalah "mentoring, on-the-job training, workshop talent development program, dan leadership sharing session. Selanjutnya dilakukan evaluasi atas pengembangan talent yang telah dilakukan.

Retensi talent merupakan upaya memberikan penghargaan dari organisasi kepada para talent agar tetap berada di talent pool. Retensi Talent dapat diberikan dalam bentuk intensif, penawaran mengikuti shortcourse atau kegiatan 
pengembangan diri tertentu, dan penghargaan bentuk lainnya”. Evaluasi, Penetapan, dan Penempatan Talent. Pada tahun 2018 sudah 2 keputusan Direktur Jenderal Pajak terkait hasil dari manajemen talenta yang dituangkan dalam pengumuman nomor PENG-163/PJ/2018 tanggal 30 April 2018 dan PENG-218/PJ/2018 tanggal 8 Juni 2018.

Tujuan atas program-program tersebut adalah dalam rangka meningkatkan kinerja pegawai DJP agar dapat mencapai tujuan organisasi yang telah ditetapkan yaitu optimalisasi penerimaan negara melalui pajak. Namun target dan realisasi penerimaan pajak dalam kurun 10 tahun terakhir yaitu tahun 2009 s.d. 2018, DJP belum dapat mencapai target penerimaan yang ditetapkan oleh pemerintah dan Dewan Perwakilan Rakyat (DPR).

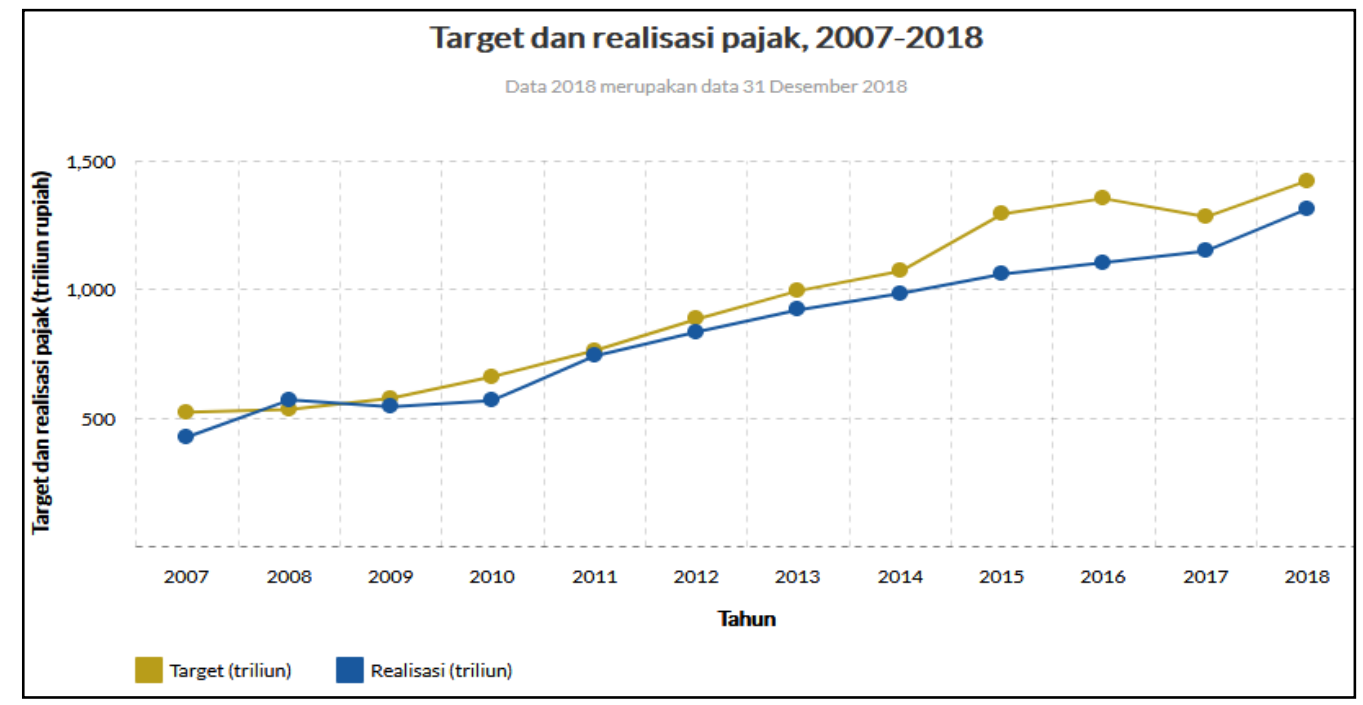

Gambar 1. Target dan Realisasi Pajak Tahun 2007-2018 Sumber:(Lokadata.beritagar.id, 2018)

Fenomena terkait semakin menurunnya kinerja organisasi dari aspek realisasi penerimaan pajak ini dapat berdampak terhadap menurunnya kinerja pegawai (employee performance) pada suatu unit kerja di DJP. Atas dampak ini akan menimbulkan permasalahan internal lainnya seperti retensi karyawan terhadap organisasi semakin menurun. Berdasarkan data bagian kepegawaian kantor pusat DJP, diketahui bahwa pada tahun 2017 telah terjadi kenaikan pegawai yang mengundurkan diri atas permintaan sendiri dari DJP dibandingkan tahun sebelumnya.

Harahap (2018) Hasil penelitiannya menunjukkan bahwa "talent Management dan knowledge management secara simultan memiliki pengaruh yang signifikan terhadap employee performance dan employee engagement namun secara parsial talent Management dan knowledge Management tidak memiliki pengaruh yang signifikan terhadap employee performance". Yang belum diteliti pada penelitian ini 
adalah pengaruh talent Management dan knowledge Management terhadap employee performance melalui retensi karyawan (employee retention) sebagai variable intervening.

Tabel 1.

\begin{tabular}{ccccccc}
\multicolumn{5}{c}{ Data Pemberhentian Pegawai Atas Permintaan Sendiri } \\
\hline No & Uraian & \multicolumn{4}{c}{ Tahun Diberhentikan } & Total \\
& & \multicolumn{2}{c}{$\mathbf{2 0 1 6}$} & \multicolumn{2}{c}{$\mathbf{2 0 1 7}$} & \\
& & Pria & Wanita & Pria & Wanita & \\
\hline 1 & Jumlah Pegawai DJP & 9 & 9 & 29 & 14 & 64 \\
\hline
\end{tabular}

Sumber: Bagian Kepegawaian KPDJP (November 2018)

Kinerja merupakan suatu fungsi dari motivasi dan kemampuan. Untuk menyelesaikan tugas atau pekerjaan, seseorang sepatutnya memiliki derajat kesedian dan tingkat kemampuan tertentu. Kinerja pegawai merupakan suatu hal yang sangat penting dalam upaya perusahaan untuk mencapai tujuannya. Salah satu cara yang dapat digunakan untuk melihat perkembangan perusahaan adalah dengan cara melihat hasil penilaian kinerja (Rivai, 2013)

Menurut Simanjuntak (2011) Kinerja adalah tingkat pencapaian hasil atas pelaksanaan tugas tertentu. Kinerja indidvidu, kinerja kelompok dan kinerja perusahaan, dipengaruhi oleh banyak faktor intern dan ekstern organisasi. Kinerja seorang pegawai pada dasarnya dipengaruhi oleh tiga faktor, yaitu faktor individual yang terdiri dari kemampuan dan keahlian, faktor psikologis dan faktor organisasi yang terdiri dari penghargaan. Penghargaan tersebut dapat berupa kompensasi yang diberikan perusahaan kepada para pegawainya. Kinerja setiap orang dipengaruhi oleh banyak faktor yang dapat digolongkan pada tiga kelompok, yaitu: kompetensi individu, dukungan organisasi dan dukungan manajemen (San et al., 2012)

Standar kinerja dapat dibuat dari uraian jabatan untuk mengaitkan definisi jabatan statis ke kinerja kerja yang dinamis. Standar kinerja dibuat untuk setiap individu dengan berpedoman pada uraian jabatan. Setiap pegawai mengusulkan sasaran-sasarannya sendiri kepada atasan langsung secara tertulis; bila kedua belah pihak menyepakati setiap sasaran, kemudian dapat dibuat pernyataan sasaran secara tertulis. Standar kinerja dianggap memuaskan bila pernyataannya menunjukkan beberapa bidang pokok tanggung jawab pegawai, memuat bagaimana suatu kegiatan kerja akan dilakukan, dan mengarahkan perhatian kepada mekanisme kuantitatif bagaimana hasil-hasil kinejanya akan diukur (Timpe, 2002)

Talent management adalah suatu proses untuk memastikan kemampuan perusahaan mengisi posisi kunci pemimpin masa depan perusahaan (company future leader) dan posisi yang mendukung kompetensi inti perusahaan (unique skill and high strategic value). Talent management juga dapat diartikan sebagai manajemen 
strategis untuk mengelola aliran talent dalam suatu perusahaan dengan tujuan memastikan tersedianya pasokan talent untuk menyelaraskan pegawai-pegawai yang tepat dengan pekerjaan yang sesuai pada waktu yang tepat berdasarkan tujuan strategis perusahaan dan prioritas kegiatan perusahaan atau bisnis perusahaan(Pella \& Innayati, 2011)

Cappelli (2008) "talent management adalah proses yang dilakukan oleh perusahaan untuk mengantisipasi dan memenuhi kebutuhan perusahaan akan sumber daya manusia. Mendapatkan orang yang tepat dengan kemampuan dan keterampilan yang tepat serta ditempatkan di dalam posisi yang tepat merupakan definisi umum dari talent management". Talent management merupakan proses yang berkesinambungan yang terdiri dari: membuat rencana kebutuhan talent, membangun citra untuk menarik best talent dari talent pool, memastikan talent yang baru masuk ke perusahaan ke dalam level produktif, melaksanakan program mempertahankan talent yang terbaik, memfasilitasi aliran talent terus-menerus ke unit, lokasi, departemen, strategi business unit (SBU) di perusahaan yang memiliki dampak paling signifikan bagi keunggulan perusahaan

Tobing (2007) "manajemen pengetahuan adalah pengelolaan knowledge perusahaan dalam menciptakan nilai bisnis dan menghasilkan keunggulan kompetitif yang berkesinambungan dengan mengoptimalkan proses penciptaan, pengkomunikasian, dan pengaplikasian semua knowledge yang dibutuhkan dalam rangka pencapaian tujuan bisnis".

Menurut Garvin (2000), " fungsi aplikasi knowladge management dalam suatu organisasi ada lima, yaitu sebagai berikut: 1) intermediation yaitu peran perantara transfer pengetahuan antara penyedia dan pencari pengetahuan, 2)externalization yaitu transfer pengetahuan dari pikiran pemiliknya ke tempat penyimpanan (repisotory) eksternal, dnegan cara se-efisien mungkin. 3)internalization adalah pengambilan (extraction) pengetahuan dari tempat penyimpanan eksternal, dan menyaring pengetahuan tersebut untuk disediakan bagi pencari yang relevan. 4)cognition adalah fungsi suatu sistem untuk membuat keputusan yang didasarkan atas ketersediaan pengetahuan dan 5)measurement yaitu kegiatan knowledge management untuk mengukur, memetakan dan mengkuantifikasi pengetahuan korporat dan kinerja dari solusi knowledge management".

Hasibuan (2011) "retensi pegawai adalah usaha mempertahankan dan/atau meningkatkan kondisi fisik, mental, dan sikap karyawan, agar mereka tetap loyal dan bekerja produktif untuk menunjang tercapainya tujuan perusahaan. Sebagai bagian dari manajemen bakat, retensi bakat menunjukkan bahwa organisasi bermaksud untuk mempertahankan karyawan dan/atau karyawan yang paling berbakat yang kemungkinan besar akan pergi". Kecemasan perputaran yang tinggi dapat dikurangi dengan mengambil pendekatan proaktif dalam mengembangkan program retensi karyawan yang efektif. "Retensi karyawan sejati membutuhkan waktu, tenaga, dan sumber daya. Bukti empiris menunjukkan bahwa lingkungan, tujuan dan sasaran organisasi yang terdefinisi dengan baik mempengaruhi retensi karyawan"(Nyanjom, 2013). 
"Retensi karyawan bertujuan untuk mempertahankan karyawan yang dianggap berkualitas, yang dimiliki oleh perusahaan, selama mungkin, karena karyawan yang berkualitas merupakan harta yang tidak tampak (intangible asset), yang tak ternilai bagi perusahaan. Retensi akan meningkat ketika karyawan ditawarkan sejumlah kompensasi dan keuntungan-keuntungan, kultur kerja yang mendukung, sekaligus adanya keseimbangan antara bekerja dan aktivitas hidup"(Messmer, 2006).

Penelitian yang dilakukan oleh Mangusho, Murei and Nelima (2015), Karuri (2015), Ngozi Nzewi (2016) tidak melibatkan variabel knowledge management sebagai variabel independent dan employee retention sebagai variabel dependen, penulis menghipotesakan bahwa variabel knowledge management memiliki korelasi yang kuat terhadap peningkatan employee performance melalui employee retention seperti halnya penelitian yang dilakukan oleh Torabi, Kyani and Falakinia(2016) yang menunjukan "bahwa variabel knowledge management berpengaruh positif signifikan terhadap employee performance".

Manajemen talenta merupakan proses berkesinambungan yang terencana dan terstruktur untuk melakukan rekrutmen, hingga mengembangkan karyawan yang memiliki banyak talenta untuk memberikan kinerja baik secara konsisten, Octavia (2018) "terdapat pengaruh positif dan signifikan dari manajemen talenta terhadap kinerja karyawan". Manajemen talenta sangat disarankan dalam birokrasi pemerintahan dalam rangka untuk meningkatkan produktifitas pegawai (Bashori, 2012). Dengan adanya manajemen talenta maka organisasi mampu meningkatkan kompetensi karyawan yang dapat berpengaruh pada peningkatan kinerja karyawan, sehingga dapat dikatakan terdapat pengaruh signifikan antara talent Management/ manajemen talenta terhadap Employee Performance /kinerja karyawan.

$\mathrm{H}_{1}$ : Diduga terdapat pengaruh signifikan variabel Talent Management terhadap Employee Performance.

Kemampuan perusahaan dalam mempertahankan sumberdaya manusia yang bertalenta merupakan upaya perusahaan dalam mengasah loyalitas karyawan terhadap perusahaan atau organisasinya. Sebagai bagian dari manajemen bakat, retensi bakat menunjukkan bahwa organisasi bermaksud untuk mempertahankan karyawan dan/atau karyawan yang paling berbakat yang kemungkinan besar akan pergi. Rahmawati (2018) dalam penelitiannya menyatakan bahwa "manajemen bakat berpengaruh positif signifikan terhadap kinerja karyawan melalui retensi di PD. BPR Regional Bank Lamongan". Employee retention yang tinggi ditentukan oleh keberhasilan organisasi dalam mengatur bakat karyawan (Mohsen, 2007). Manajemen talenta dalam suatu organisasi maka akan mampu meningkatkan retensi karyawan yang berimplikasi pada peningkatan employee performance suatu organisasi sehingga dapat dikatakan secara tidak langsung terdapat pengaruh signifikan antara talent Management/ manajemen talenta terhadap Employee Performance /kinerja karyawan melalui Employee Retention / retensi karyawan.

$\mathrm{H}_{2}$ : terdapat pengaruh signifikan dari talent Management terhadap Employee 
Retention.

Knowledge management yaitu urutan proses pembentukan, koordinasi dan aplikasi dari pengetahuan organisasi sehingga terbentuklah nilai tambah dan meningkatkan kinerja karyawan dan organisasi. Khanal and Raj Poudel (2017) "komponen proses Knowledge Management memiliki hubungan yang positif dan signifikan dengan kepuasan kerja dan kinerja karyawan”. Penerapan knowledge management dalam organisasi memudahkan lingkungan organisasi dalam mengakses informasi tersebut, sehingga dapat meningkatkan kinerja(Praditya, 2012) Dengan adanya manajemen pengetahuan maka organisasi mampu meningkatkan kompetensi karyawan yang dapat berpengaruh pada peningkatan kinerja karyawan.

$\mathrm{H}_{3}$ : Diduga terdapat pengaruh signifikan dari knowledge management terhadap employee performance.

Nyanjom (2013), mengklaim bahwa tidak diragukan lagi mempekerjakan karyawan berpengetahuan adalah penting namun retensi karyawan lebih penting. Perpaduan komprehensif dari variabel manajemen pengetahuan (KM) dan intelijen bisnis (BI) motivasi yang dapat meningkatkan retensi dan mengurangi tingginya tingkat perputaran karyawan di berbagai organisasi(Surbakti \& Ta'a, 2016). Knowledge management yang baik dalam organisasi mampu meningkatkan retensi karyawan terhadap organisasi tersebut, sehingga dapat dikatakan secara tidak langsung terdapat pengaruh signifikan antara knowledge Management/ manajemen pengetahuan terhadap employee performance /kinerja karyawan melalui employee retention /retensi karyawan.

$\mathrm{H}_{4}$ : Diduga secara tidak langsung terdapat pengaruh signifikan dari knowledge Management terhadap employee performance melalui employee retention.

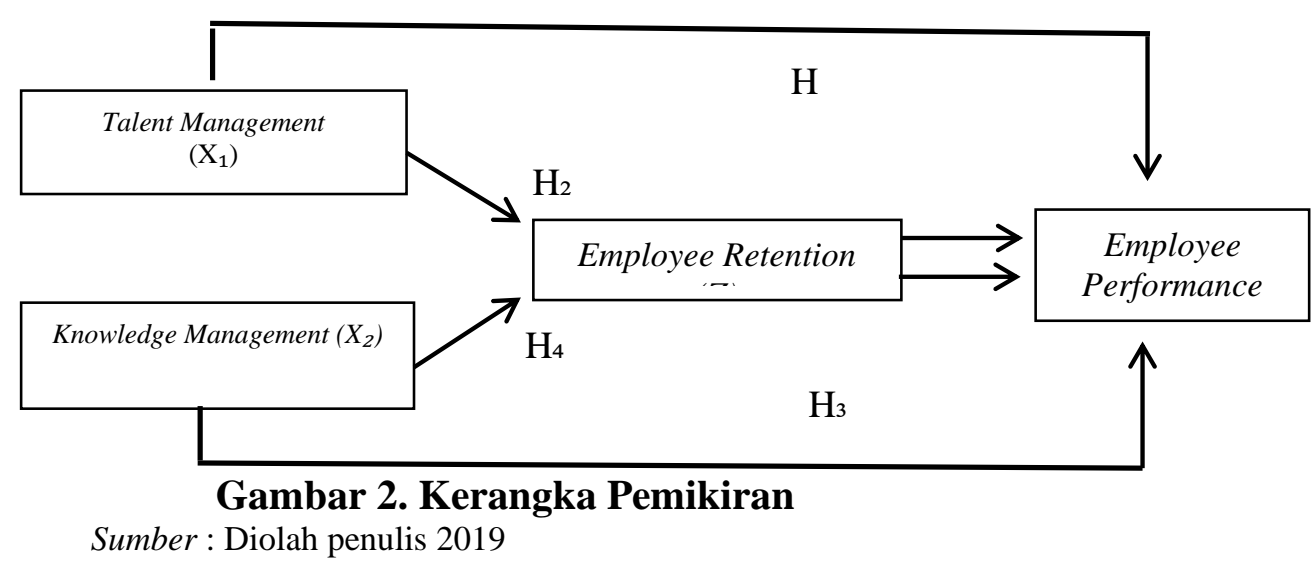

\section{METODE PENELITIAN}

Penelitian ini dilakukan dengan pendekatan berbasis kuantitatif. Arikunto 
(2014:12) mengemukakan bahwa "penelitian kuantitatif adalah pendekatan penelitian yang banyak dituntut menggunakan angka, mulai dari pengumpulan data, penafsiran terhadap data tersebut, serta penampilan hasilnya".

Populasi dalam penelitian ini adalah pegawai Direktorat Jenderal Pajak yang masuk dalam Talent Pool dengan lokasi kerja di DKI Jakarta. Populasi diambil dari data pada website internal Direktorat Jenderal Pajak dengan alamat www.https://sikka-djp/, dimana berdasarkan pengumuman Direktur Jenderal Pajak nomor PENG-09/PJ/2018) diketahui jumlah Talent Pool dengan lokasi kerja di DKI Jakarta yang menjadi populasi dalam penelitian ini sebanyak 415 pegawai.

Jenis sampel yang digunakan oleh penulis yaitu non probability sampling dengan menggunakan purposive sampling. Menurut Sugiono (2015) "pengertian purposive sampling adalah teknik penentuan sampel dengan pertimbanganatau kriteria tertentu". Adapun kriteria-kriteria yang dijadikan sebagai sampel penelitian yaitu: pegawai yang masuk dalam Talent Ready Now untuk jabatan pengawas pada tahun 2019 dan dengan lokasi unit kerja di DKI Jakarta. Berdasarkan data pada website internal Direktorat Jenderal Pajak dengan alamat www.https://sikka-djp/, dimana berdasarkan pengumuman Direktur Jenderal Pajak nomor PENG-215/PJ.01/2019 tanggal 3 Juli 2019 tentang Penetapan Talent Ready Now Pengisian Jabatan Pengawas Tahun 2019 s.d. Juni 2020 Di Lingkungan Direktorat Jenderal Pajak, jumlah pegawai yang termasuk dalam kriteria sampel penelitian ada 153 pegawai.

Teknis analisis yang digunakan dalam penelitian ini adalah analisis deskriptif. Ferdinand (2011) "tujuan dari analisis deskriptif adalah untuk mendapatkan gambaran indeks jawaban responden dari berbagai konstruk yang dikembangkan". Pada penelitian ini menggunakan metode analisis data dengan metode SEM Partial Least Square (PLS).

Menurut Ghozali (2014) mengatakan bahwa "PLS juga merupakan factor indeterminacy metode analisis yang powerful karena tidak mengasumsikan data harus dengan pengukuran Skala tertentu, jumlah sampel kecil”. Jika SEM yang berbasis kovarian mengharuskan ukuran sampel yang besar yang dapat mencakup ratusan bahkan ribuan observasi; maka PLS SEM cukup dengan menggunakan ukuran sampel yang kecil. Ukuran sampel kecil dengan persyaratan minimal adalah: 10 kali dari besarnya indikator formatif terbanyak yang digunakan untuk mengukur 1 variabel laten atau atau 10 kali dari jumlah jalur struktural terbanyak yang ditujukan ke variabel laten tertentu dalam model structural (Sarwono, 2015)

Secara ringkas langkah-langkah dalam melakukan teknik analisis data terdapat beberapa tahap pengujian, yaitu: 
Gambar 2. Tahap Pengujian dalam penelitian

Sumber : Statistik Deskriptif. (P.D, 2014)

\section{HASIL DAN PEMBAHASAN}

Penelitian ini adalah pegawai talent ready now Direktorat Jenderal Pajak Kementerian Keuangan Republik Indonesia dengan lokasi kerja di DKI Jakarta berjumlah 100 pegawai berjenis kelamin laki-laki, rata-rata usia 36-40 tahun, rata-rata lama kerja 16-20 tahun, dan memiliki riwayat pendidikan terakhir yaitu S1.

Tabel 2.

Data Karakteristik Responden

\begin{tabular}{lcccccrc}
\hline \multicolumn{1}{c}{$\begin{array}{c}\text { Jenis } \\
\text { Kelamin }\end{array}$} & Jumlah & Usia & Jumlah & $\begin{array}{c}\text { Lama } \\
\text { Kerja }\end{array}$ & Jumlah & Pendidikan & Jumlah \\
\hline Laki-laki & 72 & $31-35$ th & 20 & $5-10$ th & 34 & Diploma & 7 \\
Perempuan & 28 & $36-40$ th & 40 & $11-15$ th & 2 & Sarjana & 76 \\
& & $41-45$ th & 29 & $16-20$ th & 38 & Pascasarjana & 17 \\
& & $>45$ th & 11 & $21-25$ th & 18 & & \\
& & & $>25$ th & 8 & & \\
\hline
\end{tabular}

Sumber: Data diolah 2019

Tabel di atas menunjukan bahwa : responden yang berjenis kelamin laki-laki memiliki persentase sebesar $72 \%$. Sedangkan responden yang berjenis kelamin perempuan memiliki persentase sebesar $28 \%$, jumlah responden berdasarkan tingkatan usia dikelompokan menjadi 5 kategori yaitu: usia 25-30 tahun memiliki persentase sebesar 0\%, usia 31-35 tahun memiliki persentase sebesar 20\%, usia 36-40 tahun memiliki persentase sebesar 40\%, usia 41-45 tahun memiliki persentase sebesar $29 \%$ dan usia $>45$ tahun memiliki persentase sebesar $11 \%$. Pada penelitian ini responden yang berusia 36-40 tahun lebih mendominasi dibandingkan yang lain dan 89\% responden berada diusia 31-45 tahun, jumlah responden berdasarkan tingkatan pendidikan akhir dikelompokan menjadi 3 kategori yaitu: pada pendidikan Diploma memliki persentase sebesar 7\%, Sarjana sebesar 76\% dan Pascasarjana memliki persentase sebesar $17 \%$. jumlah responden berdasarkan lama kerja dikelompokan menjadi 5 kategori yaitu: lama kerja 5-10 tahun memiliki persentase sebesar 34\%, lama kerja 11-15 tahun memiliki persentase sebesar 2\%, lama kerja 1620 tahun memiliki persentase sebesar 38\%, lama kerja 21-25tahun memiliki persentase sebesar $18 \%$ dan lama kerja >25 tahun memiliki persentase sebesar $8 \%$.

Statistik deskriptif variabel penelitian dijabarkan pada tabel dibawah ini yang bertujuan untuk mendapatkan gambaran kecenderungan jawaban responden terhadap variabel penelitian ini terdiri dari variabel Talent Management, Knowledge 
Management, Employee Performance dan Employee Retention :

Tabel 3.

Statistik Deskriptif

\begin{tabular}{llcccc}
\hline \multicolumn{1}{c}{ Variabel } & $\mathbf{N}$ & Min & Max & Mean & $\begin{array}{c}\text { Standard } \\
\text { Deviation }\end{array}$ \\
\hline Talent Management & 100 & 3.65 & 3.91 & 3.83 & 1.16 \\
Knowledge Management & 100 & 3.59 & 4.10 & 3.85 & 1.06 \\
Employee Retention & 100 & 3.49 & 4.05 & 3.84 & 1.01 \\
Employee Performance & 100 & 3.70 & 4.11 & 3.93 & 1.04 \\
\hline
\end{tabular}

Sumber: Data diolah 2019

Berdasarkan Tabel 3. diatas, hal ini dapat dilihat dari nilai mean yang seluruhnya bernilai lebih besar 2.5 dari setiap variabel, yang artinya rata-rata responden cenderung memberikan respon positif terhadap pernyataan yang diberikan. Dari tabel tersebut terlihat besaran standar deviasi yang hampir sama untuk semua variabel, dimana standar deviasi dari kumpulan data yang sama dengan satu menunjukkan bahwa semua nilai-nilai dalam himpunan tersebut adalah hampir sama, tidak mendekati nilai rata-rata/mean.

Model struktural (inner model) pada penelitian ini terdiri dari satu variabel laten eksogen (Talent Management dan Knowledge Management) dan dua variabel laten endogen (Employee Retention dan Employee Performance).

Model pengukuran (outer model) adalah model yang menghubungkan variabel laten dengan variabel manifest. Pada penelitian ini ada 4 (empa) model pengukuran (outer model), yaitu untuk variabel laten Talent Management terdiri dari 12 pernyataan/variabel manifest dan Knowledge Management terdiri dari 10 pernyataan/variabel manifest. Kemudian untuk variabel laten Employee Retention terdiri dari 7 pernyataan/variabel manifest dan untuk variabel laten Employee Performance terdiri dari 15 pernyataan/variabel manifest

Analisa inner model analisa struktural model dilakukan untuk memastikan bahwa model struktural yang dibangun robust dan akurat. Evaluasi inner model dapat dilihat dari beberapa indikator yang meliputi: Koefisien determinasi (R2), Predictive Relevance (Q2), Goodness of Fit Index (GoF). Agar seluruh variabel dinyatakan akurat, maka langkahnya adalah menguji model struktural penelitian melalui uji $R$ Square dan $Q$ Square. Hasil output software Smart-PLS 3.0 terkait uji $R$ Square dan $Q$ Square dapat dilihat pada Tabel 4.

Tabel 4. menggambarkan bahwa Nilai $\mathrm{R}^{2}$ dari variabel laten Employee Retention sebesar 0,630 yang berarti model ini dapat dijelaskan oleh variabilitas Talent management, Knowledge Management sebesar 63\% dan sisanya dapat dijelaskan oleh variabel di luar model tersebut sebesar 37\%. Nilai variabel Employee Performance sebesar 0,871 yang menjelaskan bahwa model ini dapat dijelaskan oleh variabilitas talent management dan knowledge management sebesar 87,1\% dan sisanya sebesar 12,9\% 
E-Jurnal Manajemen, Vol. 9, No. 7, 2020 : 2704-2723

dijelaskan oleh variabel lain di luar konstruk tersebut.

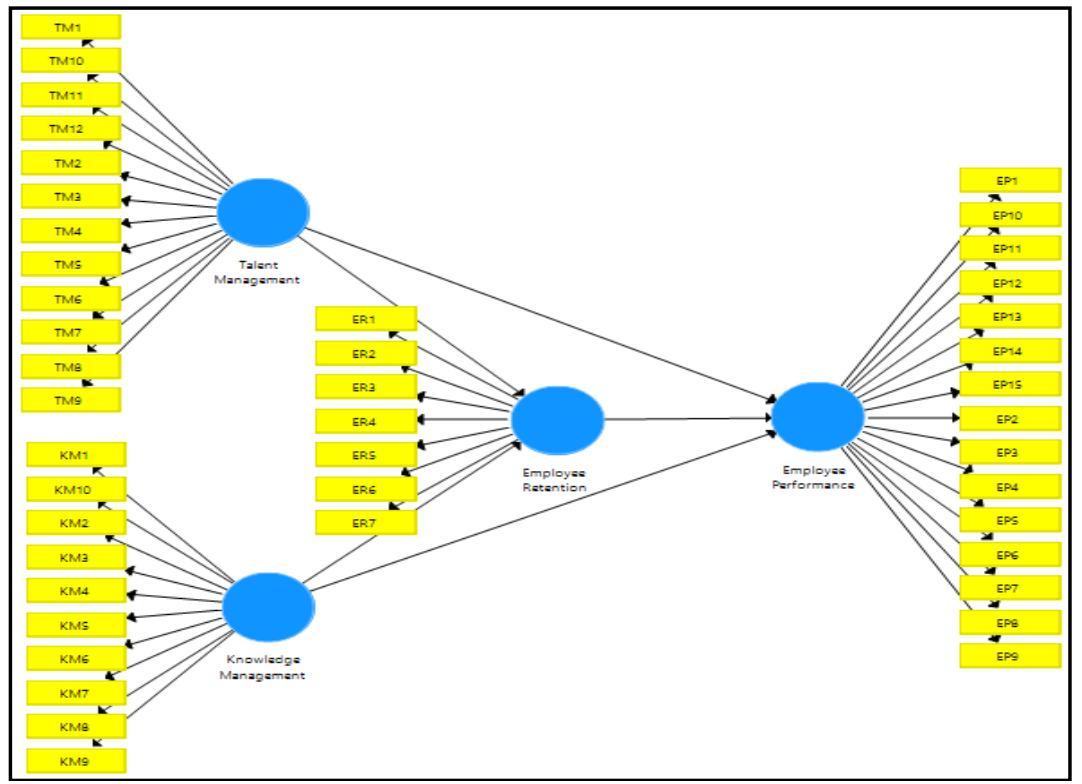

Gambar 3. Diagram Jalur

Sumber: Hasil Output PLS 3.0

Tabel 4.

Nilai R Square

\begin{tabular}{lc}
\hline & R Square \\
\hline Employee Retention & 0.630 \\
Employee Performance & 0.871 \\
\hline
\end{tabular}

Sumber: Hasil Output PLS 3.0

Uji yang dilakukan diatas merupakan uji pada outer model untuk indikator reflektif. Hasil output sofware Smart-PLS 3.0 didapat nilai Cronbach's Alpha, composite reliability dan average variance extracted (AVE) dalam penelitian ini, dapat dilihat pada Tabel 5.

Pengujian convergent validity juga dilakukan dengan melihat nilai average variance extracted (AVE). Suatu construct (variabel) dikatakan memenuhi convergent validity jika memilki nilai AVE lebih besar dari 0,5. Semua variabel dalam penelitian ini telah memenuhi convergent validity karena nilai AVE> 0.5

Reliabilitas menunjukkan tingkat konsistensi dan stabilitas indikator dalam mengukur variabel penelitian. Untuk menguji reliability construct digunakan nilai 
composite reliability. Suatu variabel dikatakan memenuhi reliability construct jika memiliki nilai composite reliability lebih besar dari 0,7 dan nilai cronbach alpha lebih besar dari 0,7. Semua variabel dalam penelitian ini reliabel karena cronbach alpha $>0.7$.

\section{Tabel 5.}

Cronbach's Alpha, Composite Reliability dan AVE

\begin{tabular}{lccc}
\hline & $\begin{array}{c}\text { Cronbach's } \\
\text { Alpha }\end{array}$ & $\begin{array}{c}\text { Composite } \\
\text { Reliability }\end{array}$ & $\begin{array}{c}\text { Average Variance } \\
\text { Extracted }(\text { AVE) }\end{array}$ \\
\hline Employee Performance & 0.968 & 0.971 & 0.693 \\
Employee Retention & 0.934 & 0.946 & 0.716 \\
Knowledge Management & 0.968 & 0.972 & 0.775 \\
Talent Management & 0.975 & 0.978 & 0.788 \\
\hline
\end{tabular}

Sumber: Hasil Output PLS 3.0, data diolah

Menguji hipotesis dapat dilihat dari nilai t-statistik dan nilai probabilitas. Untuk pengujian hipotesis menggunakan nilai statistik maka untuk alpha 5\% nilai t-statistik yang digunakan adalah 1,985. Sehingga kriteria penerimaan/penolakan Hipotesa adalah $\mathrm{Ha}$ diterima dan $\mathrm{H} 0$ di tolak ketika t-statistik > 1,985. Untuk menolak/menerima Hipotesis menggunakan probabilitas maka Ha di terima jika nilai $\mathrm{p}<0,05$.

Berdasarkan hasil pengolahan data untuk uji signifikansi (Uji t), diperoleh hasil pada Tabel 6.

Tabel 6., menunjukkan bahwa nilai uji t-statistik untuk pengaruh hubungan secara langsung, hampir semua konstruk adalah $>1.985$ dan nilai $\mathrm{P}$ Values $<0.05$ kecuali konstruk pada model talent Management terhadap employee retention yang diestimasi tidak memenuhi kriteria. Hal ini menunjukkan bahwa hampir semua variabel memiliki pengaruh yang sangat baik dan signifikan terhadap variable yang lain kecuali variabel talent Management terhadap employee retention yang memiliki nilai t-statistik < 1.985 dan $\mathrm{P}$ Values >0.05. Ini menunjukkan talent Management tidak memiliki pengaruh atau dampak dan tidak signifikan terhadap employee retention. Tabel 5 di atas juga menunjukkan bahwa nilai uji Hubungan Tidak Langsung (Specific Indirect Effects) untuk konstruk 2 model diatas ada yang memiliki pengaruh dan hubungan signifikan karena nilai T Statistik > 1.985 dan P Values < 0.05 dan ada yang tidak memiliki hubungan signifikan karena nilai $<0.05$. Hasil tersebut menunjukkan bahwa talent Management melalui employee retention tidak memiliki pengaruh dan siginifikan dalam meningkatkan employee performance. Sedangkan knowledge Management melalui employee retention memiliki pengaruh dan signifikan dalam meningkatkan employee performance. 
Tabel 6.

Hasil Uji t-Statistik

\begin{tabular}{|c|c|c|c|c|c|}
\hline & $\begin{array}{c}\text { Original } \\
\text { Sample } \\
\text { (O) }\end{array}$ & $\begin{array}{c}\text { Sample } \\
\text { Mean } \\
\text { (M) }\end{array}$ & $\begin{array}{c}\text { Standar } \\
\text { d } \\
\text { Deviatio } \\
\text { n } \\
\text { (STDEV } \\
\text { ) }\end{array}$ & $\begin{array}{c}\mathbf{T} \\
\text { Statistic } \\
\mathbf{S} \\
(\mid \mathrm{O} / \mathrm{STD} \\
\text { EV } \mid)\end{array}$ & $\begin{array}{c}\mathbf{P} \\
\text { Values }\end{array}$ \\
\hline \multicolumn{6}{|l|}{ Pengaruh Hubungan Secara Langsung } \\
\hline $\begin{array}{l}\text { Employee Retention -> Employee } \\
\text { Performance }\end{array}$ & 0.318 & 0.309 & 0.075 & 4.228 & 0.000 \\
\hline $\begin{array}{l}\text { Knowledge Management -> Employee } \\
\text { Performance }\end{array}$ & 0.297 & 0.306 & 0.104 & 2.855 & 0.004 \\
\hline $\begin{array}{l}\text { Knowledge Management -> Employee } \\
\text { Retention }\end{array}$ & 0.925 & 0.924 & 0.213 & 4.337 & 0.000 \\
\hline $\begin{array}{l}\text { Talent Management -> Employee } \\
\text { Performance }\end{array}$ & 0.383 & 0.381 & 0.093 & 4.100 & 0.000 \\
\hline $\begin{array}{l}\text { Talent Management -> Employee } \\
\text { Retention }\end{array}$ & -0.144 & -0.142 & 0.254 & 0.566 & 0.572 \\
\hline \multicolumn{6}{|c|}{ Pengaruh Hubungan Secara Tidak Langsung } \\
\hline $\begin{array}{l}\text { Knowledge Management -> Employee } \\
\text { Retention -> Employee Performance }\end{array}$ & 0.294 & 0.290 & 0.107 & 2.762 & 0.006 \\
\hline $\begin{array}{l}\text { Talent Management }->\text { Employee } \\
\text { Retention -> Employee Performance }\end{array}$ & -0.046 & -0.048 & 0.081 & 0.561 & 0.575 \\
\hline
\end{tabular}

Pada penelitian ini talent Management menunjukan pengaruh yang signifikan terhadap employee performance dengan nilai T-statistik sebesar 4.100 yang jauh lebih besar dari nilai tabel 1.985, hasil nilai P-Value 0,000 yang jauh lebih kecil dari nilai alpha 0,05 pada taraf kepercayaan $95 \%$. Hal ini juga ditunjukkan dengan nilai original sampel yang positif yaitu sebesar 0.383, yang menunjukkan bahwa arah hubungan antara $\mathrm{X} 1$ dan $\mathrm{Y}$ adalah positif. Hasil ini relevan dengan kondisi pegawai talen Direktorat Jenderal Pajak (DJP) diwilayah kerja DKI Jakarta dimana para pegawai yang masuk dalam talent pool memiliki motivasi tinggi dalam meningkatkan kinerjanya karena diantara persyaratan dalam proses rekrutment pegawai talen yang dapat diikutkan dalam program tersebut adalah pegawai-pegawai yang memiliki nilai kinerja paling tinggi diantara pegawai-pegawai yang ada diunit kerjanya.

Hasil penelitian ini sejalan dengan Octavia, H.V. dan Susilo, H. (2018), yang menyatakan bahwa "terdapat pengaruh positif dan signifikan dari manajemen talenta terhadap kinerja karyawan. Hal ini membuktikan pula bahwa talent Management merupakan faktor penting dalam meningkatkan kinerja pegawai di DJP”. Hasil tersebut didukung juga dengan penelitian yang dilakukan oleh Rahmawati (2018) manajamen talenta berpengaruh signifikan terhadap kinerja karyawan

Hasil penelitian talent Management menunjukan tidak berpengaruh terhadap employee performance melalui employee retention dimana hasil uji hubungan tidak langsung (Specific Indirect Effect) dengan nilai T-statistik sebesar 0.561 lebih kecil dari tabel 1.985 dan hasil nilai P-Value 0,575 yang jauh lebih besar dari nilai alpha 
0.05 pada taraf kepercayaan 95\%. Hal ini juga ditunjukkan dengan nilai original sampel yang negatif yaitu sebesar -0,046, yang menunjukkan bahwa arah hubungan antara $\mathrm{X} 1, \mathrm{Z}$ dan $\mathrm{Y}$ adalah negatif. Hal tersebut menjelaskan bahwa talent Management tidak memiliki pengaruh terhadap employee performance melalui employee retention.

Hasil penelitian ini tidak sejalan dengan penelitian yang dilakukan oleh Rahmawati, H.A. (2019), dalam penelitiannya menyatakan bahwa "manajemen bakat berpengaruh positif signifikan terhadap kinerja karyawan melalui retensi pegawai di PD. BPR Regional Bank Lamongan”. Kondisi hasil ini jika di analisa dari hasil penelitian, kondisi dilapangan dan karekteristik responden dimana adalah pegawai talen DJP diwilayah kerja DKI Jakarta, dapat diketahui bahwa saat disampaikan kuisioner penelitian untuk diisi para responden tersebut baru saja mendapat promosi jabatan dengan lokasi unit kerja barunya yang berada diluar pulau jawa dan sebagian besar responden tersebut mendapat promosi jabatan pada unit kerja diwilayah Indonesia bagian timur. Berdasarkan hasil olah karekteristik responden diketahui bahwa sebagian besar responden merupakan pegawai dalam usia dewasa muda atau dalam usia produktif kerja yang masih memiliki motivasi tinggi dalam mengejar kesuksesan dalam karier dan rata-rata juga merupakan keluarga baru yang kemungkinan besar memiliki anak yang masih kecil dan menduduki bangku sekolah yang mana hal ini menjadi prioritas dalam kehidupannya.

Berdasarkan kondisi responden tersebut, dapat di ambil kesimpulan yang diantara faktor yang menjadi penyebab dari tidak berpengaruhnya talent Management terhadap employee retention pegawai talen DJP diwilayah kerja DKI Jakarta adalah kondisi psikologis pegawai tersebut. Dimana saat dilakukan penelitian, kondisi psikologis responden dalam keadaan kaget dan bingung karena terpengaruhi atas pengumuman promosi jabatan yang lokasi kerjanya jauh dari hombase atau keluarga. Kondisi tersebut relevan dengan hasil dari penelitian ini dimana dari kuisioner tentang talent Management sebagian besar responden menyatakan sangat tidak setuju pada pernyataan bahwa diberi kesempatan rotasi jabatan untuk tugas dan tanggung jawab yang lebih besar.

Hasil tersebut didukung oleh penelitian yang dilakukan Nisa, Astuti and Prasetya (2016) yang menunjukan hasil tidak signifikan antara variabel talent management dan kinerja karyawan pada PT. PLN Distribusi Jawa Timur.

Pada penelitian ini knowledge Management menunjukan pengaruh yang signifikan terhadap employee performance dengan nilai T-statistik sebesar 2.855 , hasil nilai P-Value 0,004 yang jauh lebih kecil dari nilai alpha 0.05 pada taraf kepercayaan $95 \%$. Hal ini juga ditunjukkan dengan nilai original sampel yang positif yaitu sebesar 0.297, yang menunjukkan bahwa arah hubungan antara X2 dan Y adalah positif. Hasil ini relevan dengan kondisi pegawai talen DJP diwilayah kerja DKI Jakarta dimana para pegawai karena merasa mudah dan terfasilitasi oleh organisasi dalam meningkatkan pengetahuaannya sehingga memiliki motivasi tinggi dalam meningkatkan kinerjanya. Hal ini juga sesuai dengan yang disampaikan Armstrong 
(2009:149) menyatakan bahwa "manajemen pengetahuan sebagai proses atau praktek membuat, memperoleh, menangkap, berbagi, dan menggunakan pengetahuan untuk meningkatkan pembelajaran dan kinerja organisasi”.

Hasil penelitian ini sejalan dengan penelitian yang dilakukan oleh Torabi et al., (2016) yang menyatakan pula bahwa dampak Knowledge Management terhadap kinerja karyawan dan komponennya secara signifikan mempengaruhi positif kinerja SDM serta semua komponen kinerja, kecuali lingkungan. Hal ini membuktikan bahwa knowledge Management merupakan faktor penting dalam meningkatkan kinerja pegawai DJP di Jakarta.

Pada penelitian ini Knowledge Management menunjukan pengaruh yang signifikan terhadap employee performance melalui employee retention dengan hasil uji hubungan tidak langsung (Specific Indirect Effect) dengan nilai T-statistik sebesar 2.762 lebih besar dari tabel 1.985 dan hasil nilai P-Value 0,006 yang jauh lebih kecil dari nilai alpha 0.05 pada taraf kepercayaan 95\%. Hal ini juga ditunjukkan dengan nilai original sampel yang positif yaitu sebesar 0.294, yang menunjukkan bahwa arah hubungan antara $\mathrm{X}_{2}$ dan $\mathrm{Y}$ adalah positif. Pengaruh positif tersebut dapat dibuktikan dengan salah satu indicator pernyataan Knowledge Management yang memberikan pengaruh sangat kuat adalah mudah mengakses data dan/atau informasi tentang organisasi dan satu indikator pernyataan employee retention yang memberikan pengaruh sangat kuat adalah organisasi memberikan pekerjaan yang bernilai lebih dibanding bekerja di organisasi lain. Hasil penelitian ini sejalan dengan penelitian yang dilakukan oleh Putri \& Arwiyah (2019) menyatakan bahwa retensi karyawan berpengaruh positif secara signifikan terhadap kinerja karyawan dengan kontribusi $92 \%$.

Namun jika dibandingkan hasil uji hubungan langsung dan tidak langsung Knowledge Management, employee performance, dan employee retention, diketahui bahwa nilai hubungan langsung Knowledge Management terhadap employee performance memiliki nilai T-statistik sebesar 4.337 dan original sampel sebesar 0.925, dimana ini lebih besar jika dibandingkan dengan nilai hubungan tidak langsung Knowledge Management terhadap employee performance melalui employee retention yang memiliki nilai T-statistik sebesar 2.762 dan original sampel sebesar 0.294. Hal ini membuktikan bahwa variable employee retention tidak memiliki value yang besar dalam meningkatkan employee performance. Hal ini tetap membuktikan bahwa knowledge Management merupakan faktor penting dalam meningkatkan retensi dan kinerja pegawai di DJP. Oleh karena itu para pimpinan DJP harus dapat meningkatkan dan mengembangkan penerapan knowledge Management di DJP.

\section{SIMPULAN}

Berdasarkan hasil analisis dan pembahasan diatas dapat disimpulkan bahwa semakin baik dan meningkatnya Talent Management dan Knowledge Management maka secara parsial akan meningkatkan Employee Performance pada pegawai talen 
Direktorat Jenderal Pajak diwilayah kerja DKI Jakarta. Hal ini menunjukkan bahwa Talent Management dan Knowledge Management secara langsung memberikan pengaruh sangat kuat dalam meningkatkan kinerja pegawai dan organisasi Direktorat Jenderal Pajak. Sedangkan Talent Management secara tidak langsung melalui Employee Retention tidak dapat meningkatkan Employee Performance pada pegawai talen Direktorat Jenderal Pajak diwilayah kerja DKI Jakarta namun Knowledge Management melalui Employee Retention secara tidak langsung dapat meningkatkan Employee Performance pada pegawai talent DJP diwilayah kerja DKI Jakarta walaupun pengarugnya tidak sebesar jika dilakukan secara langsung. Hal ini menunjukkan bahwa Talent Management memberikan pengaruh sangat lemah dalam peningkatan retensi pegawai Direktorat Jenderal Pajak dan Employee Retention secara tidak langsung tidak memberikan pengaruh yang kuat dalam meningkatkan kinerja pegawai dan organisasi Direktorat Jenderal Pajak.

Berdasarkan uraian simpulan di atas, maka penulis dapat memberikan saran bagi Institusi Direktorat Jenderal Pajak (DJP) agar dapat meningkatkan sistem Knowledge Management yang telah berjalan dan program-program kegiatan yang terkait dengan implementasi dari system tersebut khususnya yang terkait dalam kegiatan yang dapat meningkatkan pengetahuan dan kapasitas pegawai DJP untuk menunjang pekerjaannya. Karena hal tersebut selain akan meningkatkan kinerja pegawai juga akan meningkatkan retensi pegawai untuk tetap di DJP. Selain itu Direktorat Jenderal Pajak (DJP) agar dapat memperbaiki dan meningkatkan system dan penerapan Talent Management di DJP khususnya yang terkait dengan sosialisasi tentang deskripsi pekerjaan atas jabatan yang diseleksikan dalam program Talent Management dan program pengembangan talen dengan memberikan kesempatan beasiswa pendidikan.

Adapun bagi penelitian selanjutnya, penulis menyarankan untuk mengkaji secara komprehensif tentang Talent Management, Knowledge Management dan employee retention dan menambahkan jumlah sampel penelitian untuk menghasilkan distribusi data yang lebih baik di Direktorat Jenderal Pajak Kementerian Keuangan Republik Indonesia. Selain itu, bisa menambahkan variabel employee engagement atau variabel lainnya yang berkaitan dengan Talent Management dan Knowledge Management

\section{REFERENSI}

Bashori, K. (2012). Manajemen Talenta Untuk Mengoptimalkan Produktivitas PNS. Jurnal Kebijakan Dan Manajemen PNS, 6(2), 61-73.

Cappelli, P. (2008). Talent management for the twenty-first century. Harvard Business Review.

Ferdinand, A. (2011). Metode Penelitian Manajemen Pedoman Penelitian untuk Penulisan Skripsi Tesis dan disertai Ilmu Manajemen (3rd ed.). Semarang: 
E-Jurnal Manajemen, Vol. 9, No. 7, 2020 : 2704-2723

Undip.

Ghozali, I. (2014). Structural Equation Modeling; Metode Alternatif dengan Partial Least Square (PLS).

Harahap, S. . M. (2018). Pengaruh Talent Management dan Knowledge Management Terhadap Employee Performance Performance Dengan Employee Engagement Sebagai Variabel Intervening (Vol. 5, Issue 1) [Universitas Islam Indonesia]. https://doi.org/10.1016/j.ijmachtools.2009.09.004

Hasibuan, M. S. P. (2011). Manajemen Sumber Daya Manusia. Edisi Revisi Jakarta: Bumi Aksara.

Karuri, M. (2015). Effect Of Talent Management On Employee Outcomes : A Case Study Of Central Bank Of Kenya. 151(september 2016), 10-17. https://doi.org/10.1145/3132847.3132886

Khanal, L., \& Raj Poudel, S. (2017). Saudi Journal of Business and Management Studies Knowledge Management, Employee Satisfaction and Performance: Empirical Evidence from Nepal. Saudi Journal of Business and Management Studies, 2(2), 82-91. https://doi.org/10.21276/sjbms.2017.2.2.3

Laporan Kinerja DJP. (2018). www.https://pajak.go.id

Mahmudi. (2015). Manajemen Kinerja Sektor Publik(Kedua). UPP STIM YKPN.

Mangusho, Y. S., Murei, R. K., \& Nelima, E. (2015). Evaluation of talent management on employees performance in beverage industry: A case of Del Monte Kenya Limited. International Journal of Humanities and Social Science, 5(8), 191-199. https://doi.org/10.1016/S0013-4686(02)00122-6

Messmer, M. (2006). Four Keys to Improved Staff Retention - ProQuest. Strategic Finance.

Ngozi Nzewi, H. (2016). Talent management and employee performance in selected commercial banks in Asaba, Delta State, Nigeria. European Law Review, 8(1), 01-01. https://doi.org/10.21859/eulawrev-08015

Nisa, R. C., Astuti, E. S., \& Prasetya, A. (2016). Pengaruh Manajemen Talenta dan Manajamen Pengetahuan Terhadap Kinerja Karyawan (Studi pada Karyawan PT. PLN (Persero) Distribusi Jawa Timur, Surabaya). Jurnal Administrasi Bisnis, 32(2), 141-148. 
Nyanjom, C. R. (2013). Factors influencing employee retention in the state corporations in Kenya. School of Business, University of Nairobi.

Octavia, H. V. (2018). Pengaruh Manajemen Talenta Terhadap Kinerja Karyawan. Jurnal Administrasi Bisnis, 60(2), 186-191.

P.D, S. (2014). Metode penelitian pendidikan pendekatan kuantitatif.pdf. In Metode Penelitian Pendidikan Pendekatan Kuantitatif, Kualitatif Dan R\&D.

Pella, A. D., \& Innayati, A. (2011). Talent Management: Mengembangkan SDM untuk Mencapai Pertumbuhan dan Kinerja Prima. Gramedia Pustaka Utama. http://kin.perpusnas.go.id/DisplayData.aspx?pId=10786\&pRegionCode $=T E L$ UNI\&pClientId=116http://kin.perpusnas.go.id/DisplayData.aspx?pId=10786\& pRegionCode $=$ TELUNI\&pClientId $=116$

Putri, I. D., \& Arwiyah, M. Y. (2019). Pengaruh Retensi Karyawan Terhadap Kinerja Pegawai Pata PT Kalacitra Utama Jakarta. 6(2), 4494-4500.

Putrianty, A. D., \& Kurniady, D. A. (2014). Pngaruh Kepemimpinan Transformasional, Kepuasan Kerja Guru Terhadap OCB Guru TK SeKabupaten Kudus. 1, 1-11.

Rahmawati, H. A. (2018). Pengaruh Manajement Talenta Terhadap Kinerja Lintasari Kota jakarta. Jurnal IManajemen Indonesia (JIMI, 7(2), 419-429.

Rivai, V. (2013). Manajemen Sumber Daya Manusia. Manajemen Sumber Daya Manusia Untuk Perusahaan Dari Teori Ke Praktik.

San, O. T., Theen, Y. M., \& Heng, T. B. (2012). The Reward Strategy and Performance Measurement ( Evidence from Malaysian Insurance Companies ). International Journal of Business, Humanities and Technology.

Simanjuntak, P. (2011). Manajemen dan Evaluasi kinerja. In Lembaga Penerbit Fakultas Ekonomi Universitas Indonesia: Jakarta.

Sugiono. (2015). Metodologi Penelitian. ALfabeta.

Surbakti, H., \& Ta'a, A. (2016). Improving Employees Retention Rate Through Knowledge Management and Business Intelligence Components. Proceedings of Knowledge Management International Conference (Kmice) 2016, August, $13-17$. 
E-Jurnal Manajemen, Vol. 9, No. 7, 2020 : 2704-2723

Target dan Realisasi Pajak 2007-2018. (n.d.). Lokadata.Beritagar.Id. https://lokadata.beritagar.id/chart/preview/target-dan-realisasi-pajak-20072018

Tobing, P. (2007). Knowledge Management-Konsep Arsitektur dan Implementasi. Graha Ilmu.

Torabi, M. H. R., Kyani, A., \& Falakinia, H. (2016). An Investigation of the Impact of Knowledge Management on Human Resource Performance in Management of Keshavarzi Bank Branches in Tehran. Procedia - Social and Behavioral Sciences, 230(May), 471-481. https://doi.org/10.1016/j.sbspro.2016.09.059 